Volume: 2 | Volumen 2 | Número 1 | Number 1 | pp. 51 - 68 ISSN: 2634-355X (Print) | ISSN: 2634-3568 (Online) journals.tplondon.com/yeiya

First Submitted: 29 January 2021 Accepted: 31 May 2021 DOI: https://doi.org/10.33182/y.v2i1.1579

\title{
Pedagogías Críticas y Psicología Latinoamericana: diálogos para una pedagogía desde el sur global
}

\author{
Hugo Adrian Morales ${ }^{1}$
}

\section{Resumen}

El siguiente trabajo, se trata de una revisión teórica conceptual sobre las diferentes modalidades que expresa el capitalismocolonial en la región y como se re-articula el poder colonial a través de ciertos discursos, políticas y estrategias en el sistema educativo, reproduciendo modalidades de subjetivación coloniales y respondiendo a una mirada del mundo, la sostenida por la geopolítica del conocimiento. Una aproximación a los aportes sobre la colonialidad del poder y la colonialidad del saber de Aníbal Quijano, la Educación Liberadora de Paulo Freire, las Pedagogías Criticas y la Psicología Latinoamericana, re-significadas y re-pensadas a la luz de los diversos movimientos populares, indígenas, feministas, campesinos, entre otros, nos permiten avanzar en el diseño de pedagogías criticas, populares e interculturales desde el sur global.

Palabras clave: Capitalismo; colonialismo; pedagogia; psicología; interculturalidad

\section{Critical Pedagogies and Latin American Psychology: Dialogues for a Pedagogy From the Global South}

\begin{abstract}
The work investigates the different modalities that colonial-capitalism expresses in the region and how colonial power is re-articulated through certain discourses, policies and strategies in the educational system, reproducing colonial modalities of subjectivation and responding to a glance of the world, sustained by the geopolitics of knowledge. An approach to the contributions on the coloniality of power and the coloniality of knowledge by Anibal Quijano, the Liberating Education of Paulo Freire, Critical Pedagogies and Latin American Psychology, re-signified and re-thought in the light of the various popular movements, indigenous, feminists, peasants, among others, allow us to advance in the design of critical, popular and intercultural pedagogies from the global south.
\end{abstract}

Keywords: Capitalism, colonialism; pedagogy; psychology; interculturality

\section{Introducción}

Como es una negación sistemática del otro Una decisión furiosa de privar al otro de todo atributo

De humanidad, el colonialismo empuja al pueblo Dominado, a plantearse constantemente la pregunta ¿Quién soy en realidad?”

\footnotetext{
${ }^{1}$ Hugo Adrian Morales, Doctor en Psicología-Docente de la FAPSI-UNSL-Integrante Centro de Pensamiento Crítico "Pedro Paz”. Integrante del comité de Doctorado de la Facultad de Psicología de la Universidad Nacional de San Luis, Argentina. Correo: hamorales2000@gmail.com.
} 
Debemos considerar tres aspectos fundamentales que hacen al siguiente capítulo. El primero, tiene que ver con la descripción de algunos indicadores actuales del sistema capitalista y su vínculo con el sistema educativo, lo haremos con la finalidad de describir cómo se actualizan discursos y estrategias de carácter colonial de la geopolítica del conocimiento. Por ejemplo, se puede pensar, que ciertos discursos del Fondo Monetario Internacional (FMI), Banco Mundial (BM), Banco Interamericano de Desarrollo (BID), entre otros organismos internaciones, revitalizan los discursos de ${ }^{2}$ Sepúlveda o Maqueda de antaño, dos discursos paradigmáticos sobre la conquista, los pueblos originarios y su dominación, Sepúlveda justifica la guerra justa sobre los indios por ser los "esclavos naturales", seres inferiores, pecadores, que hay que eliminarlos si fuera necesario por oponerse a la dominación natural y justa de los seres superiores "occidente" y de Bartolomé de las Casas, quien los consideraba seres racionales y libres, dotados de cultura, que va a denunciar la declaración de inferioridad como justificación de la explotación y el saqueo por parte de occidente (Dussel, 1992). Es decir, en los discursos vigentes sobre el sur global, se actualizan ciertas modalidades de subjetivación coloniales de la conquista.

Segundo, el aporte de ${ }^{3}$ Aníbal Quijano para describir cómo la colonialidad del poder, encuentra legitimidad en la colonialidad del saber cómo brazo ejecutor. La originalidad de Quijano, radica en la descripción de las rearticulaciones del poder colonial, siendo el sistema educativo uno de sus principales reproductores. Quijano describe las nuevas categorías mentales del orden colonial, como los nuevos procesos de subjetivación, eje central para pensar la Psicología y la Pedagogía en la región.

Por último, la descripción de la colonialidad del poder de Aníbal Quijano, y el análisis de una de sus aristas como la colonialidad del saber, permite avanzar en la comprensión de las herencias coloniales del saber, en este caso particular, ${ }^{4}$ Paulo Freire podría ser un punto de partida en el redescubrimiento de un dialogo intercultural. Una breve reseña de ${ }^{5}$ Simón Rodríguez, ${ }^{6}$ Carrillo Torres, entre otros, hasta ${ }^{7}$ Catherine Walsh, nos permitirá comprender a los habitantes de la región latinoamericana, la relevancia de la Educación Liberadora de Paulo Freire, en la posibilidad de redescubrir saberes y experiencias en el diálogo intercultural como alternativa a la unidimensionalidad eurocéntrica.

\footnotetext{
${ }^{2}$ Celebre debate en la denominada junta de Valladolid y que consistió en dos posturas sobre la conquista de América en 1550 1551. La postura de Bartolomé de las Casas quien sostenía que los habitantes de América tenían alma y eran seres humanos y no merecían el saqueo y el genocidio llevado adelante por los conquistadores y Ginés de Sepúlveda quien defiende la conquista y el genocidio considerando seres inferiores a las comunidades indígenas.

3 (1930-2018) Sociólogo y Teórico Político Peruano. Uno de los principales referentes de la teoría de la dependencia en América Latina. autor de diferentes libros vinculados a los conceptos de colonialidad, modernidad y descolonialidad.

4 (1921-1997) Pedagogo y filósofo Brasilero, nacido en recibe en el seno de una familia humilde llego a ser considerado el pedagogo de los oprimidos. Fue perseguido y exiliado por la dictadura de Brasil, fue creador de un revolucionario método de alfabetización y referente de la educación liberadora.

5 (1769-1854) Escritor y Educador Venezolano, Fue maestro del libertador Simón Bolívar y gran pensador de la educación popular en el continente. Autor de obras para la independencia y la integración del continente americano.

${ }^{6}$ Educador Popular e investigador social colombiano. Autor de libros y artículos con temáticas vinculada a la Educación Popular, Los Movimientos Sociales y las Investigaciones Alternativas.

${ }^{7}$ Intelectual, militante y referente del Pensamiento Decolonial en América Latina. Profesora y directora del Doctorado en estudios culturales latinoamericanos en la Universidad Andina Simón Bolívar de Ecuador.
} 
Ignacio Martín-Baró referente de la psicología de la liberación decía sobre Paulo Freire, en relación posicionamiento epistémico de los científicos en la construcción de un campo de estudio:

"No se trata de que nosotros pensemos por ellos, de que les transmitamos nuestros esquemas o de que les resolvamos sus problemas; se trata de que pensemos y teoricemos con ellos y desde ellos. También aquí acertó la intuición pionera de Paulo Freire, quien planteó la pedagogía «del» oprimido y no «para» el oprimido; era la misma persona, la misma comunidad la que debía constituirse en sujeto de su propia alfabetización conscientizadora, la que debía aprender en diálogo comunitario con el educador a leer su realidad y a escribir su palabra histórica." (Martín-Baró, 1986: 9).

Repensando la advertencia de Paulo Freire, sobre la premisa que la pedagogía dominante era la de la clase dominante, por lo tanto, la pedagogía debía partir del oprimido, de lo subalterno, de lo popular, de lo indígena, del sur global (Freire, 2012). Por este motivo, los diálogos de la Psicología de la Liberación y la Educación Liberadora, no deben establecerse desde lo existente en la región, por el contrario, deben poder redescubrir lo no existente, en cuanto experiencias y saberes omitidos por la geopolítica del conocimiento. Para ello, Aníbal Quijano y Paulo Freire, resultan antecedentes cercanos, para comenzar a diálogos entre los campos de estudios del sur global.

\section{Metodología}

La necesidad de repensar el diseño e implementación de las políticas educativas en América Latina en general y Argentina en particular, surge de las insatisfacciones que genera el sistema educativo al momento de comprender la realidad de América Latina. Es decir, el desfasaje que se presenta entre el diseño de las políticas educativas, los procesos de formación y lo que sucede "afuera" de la academia. El trabajo es de tipo teórico-reflexivo, de características metodológicas cualitativas y centradas en el análisis bibliográfico. En este sentido, se toman algunos indicadores del sistema capitalista-colonial en la región y sus rearticulaciones en el diseño e implementación de políticas educativas, se analizan a la luz de ciertos interrogantes planteados por las Pedagogías Criticas, la Educación Liberadora, la Educación Popular y psicología de la liberación.

Respecto a los aportes de la colonialidad del poder y del saber de Aníbal Quijano y a la introducción de algunas categorías como colonialismo, decolonialidad, razón instrumental, entre otros, son pensadas a la luz de lo que algunos autores/as denominan "giro decolonial", giro que vendría a complementar la categoría de "descolonización" utilizada por las ciencias sociales a finales del siglo XX. El giro decolonial consiste en dos puntos centrales, primero comenzar a hablar de sistema-mundo europeo/euro-norteamericano-capitalista/patriarcalmoderno colonial y no solo sistema-mundo-capitalista porque con ello se cuestiona abiertamente el mito de la descolonización y la tesis de que la posmodernidad nos conduce a un mundo desvinculado de la colonialidad, de esta manera, el capitalismo global contemporánea, resignifica en un formato posmoderno las exclusiones provocadas por las jerarquías epistémicas, espirituales, raciales/ étnicas y de género/sexualidad desplegadas por la modernidad. De este modo, las estructuras de larga duración formadas durante los siglos XVI y XVII continúan jugando un rol importante en el presente (Castro Gomez, Grosfoguel, 2007). En segundo punto, consiste en el giro decolonial que intenta dirigirse y resignificar las heterarquias de las múltiples relaciones raciales, epistémicas, económicas y de género que la 


\section{Pedagogías Críticas y Psicología Latinoamericana: diálogos para una pedagogía desde el sur global}

primera descolonización dejo intactas. En definitiva, el mundo del siglo XXI necesita una decolonialidad que complementa la descolonización llevada a cabo en los siglos XIX y XX.

\section{Breve descripción de algunas rearticulaciones del capitalismo en la region}

Suponer una crisis del capitalismo, resulto ser una de las tantas estrategias que encontró el capital, para socializar sus resultados, sus costos, y así seguir proponiendo nuevas recetas, es decir, continuar mutando en la aplicación de sus políticas. Esta fórmula fue durante muchas décadas, una de las tantas estrategias de reconversión del capital. Lo paradójico en América Latina, resultó ser que la denominada crisis, fue parte del desarrollo histórico, inherente a la constitución misma de la región.

Lo que indudablemente resulta más temible en la denominada crisis del capital actual, son las secuelas de la acumulación desmedida del capitalismo voraz, es decir, sumados a la lógica misma del capital, como gobiernos sin poder, consumidores por ciudadanos, sociedades sin proyectos, democracias sin democracias, ya se puede hablar de cambios irreversibles en lo que algunos movimientos sociales y ecologistas en la región denominan la "huella ecológica", una crisis que se asoma ya con evidencias de gran notoriedad (alimenticia, climática, económica y energética) muestran al desnudo, una crisis irreversible del paradigma que está devorando a los seres humanos y a la naturaleza a escala global. Indudablemente lo que algunos llaman pos-capitalismo, está mostrando sus efectos más destructivos, siendo un modo de llevar a la humanidad a un salto al vacío.

Sumado al deterioro ambiental, aparecen también las insatisfacciones que generó el sistema actual, es decir, la certeza de que el crecimiento económico no logró resolver los problemas de la pobreza y marginalidad, incluso se fueron profundizando. En poco más de una década, el producto bruto mundial se ha duplicado, presenciamos épocas donde por primera vez en toda la historia de la humanidad, existen abundancia de bienes de todo tipo, los bienes disponibles superan en varios miles la capacidad de satisfacción de las necesidades de los seres humanos, pero así mismo, la marginalidad, pobreza, y el abandono aumentan considerablemente en su extensión.

Al mismo tiempo, se hace evidente la crudeza del paradigma capitalista, aparecen regiones que están intentando llevar adelante trasformaciones políticas, culturales y económicas que muestran otras formas de vida posible, no solo como movimiento contra hegemónico de denuncia e impugnación, sino como alternativa real a un modo de producción destructivo, mostrando alternativas más armónicas y sustentables. Las experiencias de Bolivia y Ecuador con el "Buen Vivir" o el "Vivir Bien" (Elorza, 2015), el zapatismo como experiencia revolucionaria desde abajo (Zibechi, 2016) entre otras.

La existencia de estas experiencias regionales, traen consigo la problematización de las nociones de "desarrollo" y "progreso" como marcos conceptuales de las políticas regionales, sobre todo en políticas educativas diseñadas para la región, sabemos que pocos constructos en la historia del siglo XX, han tenido un papel tan protagónico como es el concepto contemporáneo de desarrollo, concepto o noción que alude a un tipo de dispositivo político, ideológico y científico, que se convertiría en el sello de las relaciones de poder en el capitalismo global, y que luego de la segunda guerra mundial, encontraría en América Latina un terreno fértil para la experimentación de las "políticas de desarrollo", promovidas por organismos internacionales y adoptadas por los propios Estados latinoamericanos (Carrizo, 2011). La 
rearticulación del poder colonial, que produce la noción de desarrollo luego de la segunda guerra mundial, actualiza la noción de desarrollo planteada por Enrique Dussel como categoría colonial, es decir, el desarrollo tiene una dirección en el tiempo y en el espacio, dirección que tiene una fundamentación ontológica e histórica que la dirige, en este caso, Europa como centro, principio y fin de la historia universal (Dussel, 1992)

En paralelo a la idea de progreso, y como forma de promoverla en la región, promediando la mitad de siglo XX y finalizada la segunda Mundial, comenzaron a crearse organismos internacionales de "ayuda" y "colaboración” para los denominados países subdesarrollados, como una forma de expandir el capitalismo colonial: el BM en 1944, FMI en 1945, ONU en 1945, OEA en 1948, y qué decir, de organismos específicos, para la periferia colonial como BID en 1959; así como también el programa denominado "Alianza para el progreso" (habría que preguntarse ¿progreso para quién?) en 1961.

Estos organismos regionales fueron, en su gran mayoría, intentando sumir a la población en dos grandes ejes, el primero, insertar a América Latina en la esfera del Primer mundo, mediante préstamos, ajustes y recetas que precisamente generaron todo lo contrario, y por otro lado, la necesidad de instalar un idea de progreso que impidiera el desarrollo de opciones no capitalistas en la región (Cuba, Chile). Por supuesto que el FMI, denominado por Ziegler (2002) como "los bomberos pirómanos" del universo, llevaron la miseria como caballo de Troya del "progreso" a escala global.

La premisa de que cualquier país del mundo, lograría convertirse en desarrollado por el simple hecho de cumplir con una receta económica, comenzó rápidamente a mostrar falencias, porque la visión simplista, para nada casual, de que los países denominados de "tercer mundo" o "subdesarrollados" podían llegar a estar en un estadio previo a la utopía del "desarrollo", al contrario, a situación de subdesarrollo es precisamente una situación diferenciada y estructuralmente distinta a la de desarrollo, incluso generada y limitada por la existencia misma de las países desarrollados.

La breve descripción de la emergencia de los organismos internacionales, resulta ejemplificador en dos puntos centrales, que hacen a comprensión de la necesidad de redefinir los campos de estudio del sistema educativo, a fin de comprender las rearticulaciones del poder colonial. La primera, para evidenciar la vigencia de las lecturas que Juan Ginés de Sepúlveda en la primera parte del siglo XVI, hace sobre los pueblos de los nuevos territorios anexados a Europa, discurso actualizado y maquillado en algunos matices, que no dejan de evidenciar cómo se revive la visión sobre los "esclavos naturales" de la visión aristotélica, como también lo aportado por Enrique Dussel (1992), sobre las explicaciones de la dominación "justa y natural" por ser seres inferiores y causa culpable de nuestra propia destrucción, estos discursos se actualizan en la actualidad con total naturalidad, dice De Sousa Santos al respecto:

"Con matices, el paradigma de Sepúlveda es el que prevalece todavía hoy marcando la posición occidental sobre los pueblos amerindios y africanos. Expulsada de las declaraciones universales y de los discursos oficiales es, sin embargo, la posición que domina las conversaciones de los agentes de occidente en el tercer mundo, ya sean embajadores, funcionarios de la ONU, del Banco Mundial o del Fondo Monetario Internacional, empresarios, etc. Es ese discurso privado sobre negro e indios lo que moviliza subterráneamente los proyectos de desarrollo después embellecidos 
públicamente con declaraciones de solidaridad y derechos humanos (De Sousa Santos, 2009: 221).

El segundo punto se desprende del primero, la actualización o rearticulaciones del poder colonial según Quijano, tiene que ver con la vigencia del paradigma capitalista-colonialista en la construcción de la subjetividad regional. Si podemos visualizar estas permanencias ideológicas-políticas-epistémicas, podremos comprender cómo se manifiesta la racializaciòn de las divisiones del trabajo como rearticulación del poder colonial, evidenciando la colonialidad de la vida cotidiana. Veremos a continuación cómo se ejemplifican algunas rearticulaciones del poder colonial, en el paradigma de la educación hegemónica en la región.

\section{Breve descripción de algunas lógicas del capitalismo global en el sistema educativo regional}

El análisis y lectura de las denominadas crisis estructurales y coyunturales de los modelos hegemónicos actuales, llevan consigo la necesidad de problematizar ciertas categorías centrales en las políticas de sostenimiento de tal dominación, por ejemplo al indagar sobre políticas educativas, estados pedagógicos, políticas públicas, praxis educativas alternativas, o incluso la noción de pedagogías libres, debemos remitirnos a lo que ha significado la educación como práctica de sostenimiento y homogeneización de un sistema dominante a lo largo de varios siglos en nuestra región.

Esta lógica, que permite articular poder y consenso, puede hacerse más explícita, si se analizan determinadas políticas educativas de mitad de siglo en adelante, y cómo la noción de desarrollo ha ocupado un eje central en sus implementaciones, si pensamos por ejemplo en la Argentina, en la década de los " 90 ", las políticas educativas jugaron un papel central en la agenda global de las políticas vinculadas al desarrollo de los países. Las inversiones en políticas educativas, fueron pensadas y organizadas de acuerdo al paradigma de desarrollo que sostienen los organismos internacionales. En conclusión, la preocupación global deviene precisamente porque la educación cumple un rol, que va más allá de las particularidades educativas, sus funciones sociales, políticas, culturales y económicas llevaron a pensar en la educación como una de las tantas herramientas de homogeneización cultural y consenso social. Es decir, la educación como la rearticulación del poder hegemónico occidental.

En el análisis holístico de los nuevos modelos de acumulación del capital, podemos visibilizar, cómo estos modelos son trasladados a las políticas educativas, ahí podremos ver la emergencia de un nuevo modelo de acumulación y crecimiento, basado fundamentalmente en el papel del capital humano, es decir, la educación es la nueva moneda de la oportunidad, basados específicamente en el éxito individual. Por este motivo, se le atribuye un papel que garantiza la inserción de los individuos en un mercado laboral cada vez más flexible, inestable y competitivo; asimismo se percibe como una de las principales inversiones para garantizar el desarrollo, la competitividad y el crecimiento nacional, a consecuencia de estos procesos, los discursos políticos hegemónicos hacen uso de la globalización y de sus efectos (Tarabini, 2010).

Además, hay que tener en cuenta que, en un contexto de globalización, la creciente demanda de educación va acompañada de su también creciente insuficiencia como estrategia 
para garantizar la inclusión socio-laboral. Esta es una de las mayores paradojas del proceso de globalización, por lo general, ausente en los discursos hegemónicos que guían la construcción e implementación de la agenda global (Filmus, 2011). Lo desarrollado, ejemplifica a grandes rasgos, cómo el paradigma capitalista, a través del sistema educativo, intenta instalar los problemas de desigualdad social, en componentes individuales y sin historia, la psicología en general, resulta una de sus aristas. La lógica capitalista no solo intenta homogeneizar, también intenta, mediante la lógica de progreso y desarrollo, la rearticulación de la geopolítica del conocimiento occidental.

Existe una multiplicidad de factores que pueden dar cuenta de la imposibilidad de las políticas educativas actuales, como políticas destinadas a la erradicación de la pobreza, Tarabini nos lo ejemplifica en tres principios fundamentales:

"Hay tres grandes razones que permiten explicar los límites de la agenda global para el desarrollo: en primer lugar, olvida que a pesar de que la educación es cada vez más necesaria, a su vez, es más insuficiente como estrategia única para reducir la pobreza y estimular el desarrollo; en segundo lugar, se trata de una agenda que sigue basándose en la ortodoxia del CV y que, por tanto, no altera la esencia del neoliberalismo; en tercer lugar, la agenda omite la desigualdad social y educativa como objetivos explícitos a abordar.(Tarabini, 2011: 9)

Las urgencias que pronuncian los que diagraman la agenda educativa, vinculan la educación al nivel de producción hegemónico, evitando problematizar las paradojas que hacen que, aunque la educación sea cada vez más necesaria, termina siendo cada vez más insuficiente como herramienta de cambio social. En cierta medida, poco interesa la pobreza y la marginalidad, lo que interesa es el crecimiento y progreso, en esa lógica se necesita mucha mano de obra, y pocos ciudadanos.

En el intento de globalizar al mundo, invisibilizando sus asimetrías, se implementaron programas y teorías destinadas a pensar en la educación como una herramienta de reducción de pobreza, pensemos en dos ejemplos en la región, la Teoría del Capital Humano y de la Acción Racional como sustento teórico, ambas teorías vienen a legitimar la idea, de que será la educación el mecanismo que permitirá la superación de la pobreza.

La Teoría del Capital Humano, en su versión cercana a la perspectiva neo-clásica (versión empleada por el neo-liberalismo), considera que la educación es una inversión que incrementará la productividad, beneficiando tanto al individuo como a la sociedad; y que el mercado será, mediante el libre juego de oferta y demanda, el mejor asignador de los recursos. Como se puede apreciar, para esta perspectiva, la educación es un determinante esencial para el crecimiento y desarrollo económico y el mercado su ordenador (Enriquez y Di Pascuale, 2015). Además del contenido culpabilizante de la teoría, por reducir la pobreza a la incapacidad del individuo, formula la "ilusión" de pensar que la educación brindara los recursos y habilidades necesarias para la conversión de un "individuo pobre" en un sujeto productivo, con sus consecuentes ganancias y mejoras en la calidad de vida.

En ese circuito productivo, se necesita legitimar la idea de "individuo libre", entonces surge la Teoría de la Acción Racional, donde prima la idea de que el ser humano es un individuo 


\section{Pedagogias Críticas y Psicología Latinoamericana: diálogos para una pedagogía desde el sur global}

que tiene capacidad racional, tiempo suficiente y equilibrio emocional, para seleccionar la mejor opción en función de sus propios intereses, por lo tanto, dependerá de su decisión, si desea vivir o no en situaciones de marginalidad, con todos las consecuencias que implica esta afirmación.

En este horizonte teórico, el centro de la política educativa destinada a superar la pobreza, consiste en dejar libre al individuo o poner a su disposición el ingreso necesario, para que él elija dónde y cómo educarse, en función de las ofertas existentes en el mercado. Para este enfoque, el Estado no debe intervenir, porque no sabe ni le corresponde administrar los recursos destinados a la educación; por ello, deja la oferta educativa en manos del mercado (privatización) y la demanda en manos del individuo, quien, por ser un consumidor racional, compra y supervisa el producto llamado educación. Sin embargo, estas teorías homogeneizantes, reduccionistas y neoliberales, en definitiva coloniales, en su tratamiento único, encubren o esconden el dilema de otras pobrezas, que juegan un rol importante en el círculo vicioso de la reproducción y legitimación de la pobreza económica y la injusticia social.Pero la utilización de determinadas categorías, como eufemismos de un modo de producción dominante, no es nueva ni mucho menos original. Pensemos en la política oligárquica, liberal de siglo pasado en Argentina, donde la pedagogía dominante, estaba montada como "instrucción pública", orientada ideológica y prácticamente al servicio de la civilización eurocéntrica, una especie de política pedagógica para el triunfo de la civilización sobre la barbarie, donde Domingo Faustino Sarmiento arquetipo de "instructor publico" tuvo una verdadera pasión por la escuela primaria, considerándola un medio para la modificación de las costumbres, es decir, para templar el "alma salvaje" del mestizo y del indio, en definitiva, para civilizar. En el esquema sarmientista, el progreso tendría como propósito la promoción de la cultura eurocéntrica como única cultura validada (Puiggros, 1986). Aquí también, así como en los discursos de los organismos internaciones actualizan los discursos de Sepúlveda antes mencionados, quien define el "indio como esclavo natural", Sarmiento actualiza en el sistema educativo, la civilización como proyecto emancipador, es decir, las diferentes facetas de las teorías educativas de la región, se encauzan en diversas formas de actualización de un orden colonial.

Ahora bien, pensemos en un caso paradigmático y bastante específico a nivel local. En Argentina, desde los " 90 " que se viene intentando proponer la interculturalidad en la agenda y planificación de determinadas políticas públicas educativas. Proyecto que en el fondo terminó siendo un proyecto paradójicamente inclusivo y hegemónico, evitando problematizar la matriz colonial aún vigente, es decir, evitando construir un proyecto pedagógico-políticocrítico que pueda socavar las estructuras coloniales de base, de esta manera, son y fueron propuestas que continuaron siendo funcionales a un proyecto que deshumaniza, inferioriza y homogeniza (Norgvlamtuleayiñ, 2009).

Las problemáticas entre políticas de estado y discusiones interculturales, presenta diferentes especificidades al interior de la región, cada país tiene sus dilemas de acuerdo a sus poblaciones, historias y discusiones. En la Argentina en particular, el Estado argentino desde su conformación histórica, comienza un periodo de legalización de sus territorios amparándose en el derecho Romano, sistema jurídico occidental, sosteniendo en su carta marga de 1853 como principios elementales: mantener el trato pacifico con los indios 
(invisibilizándolos, saqueándolos, despojándolos y demás), proveer la seguridad de la frontera, y por supuesto, convertir a los indios al catolicismo.

Sobre esos principios elementales, toda la política educativa estuvo orientada a la creación y conformación de una "identidad nacional", que va a ir acompañada del exterminio, negación y persecución de la denominada "barbarie", es decir, todo aquello que se oponga al proyecto civilizatorio occidental. El proyecto civilizatorio sarmientino, consistió en profundizar la matriz unicultural y eurocéntrica, que terminara legitimando la apropiación, exterminio y despojo de los pueblos originarios hasta el día de la fecha. De ahí en adelante, la fundamentación del sistema educativo, no solamente estará orientada a la negación de culturas autóctonas, también va a consistir en una sobrevaloración de las cultura eurocéntrica, con la intención de uniformar las culturas, asimilando las culturas consideradas "inferiores" a la "cultura nacional", desde la cual, se modelo el prototipo de argentino monocultural.

Como continúan sosteniendo las comunidades mapuches en territorio argentino, en el marco de la educación rígida e inflexible desde 1884 (ley 1420), que a pesar de algunas modificaciones, no ha perdido su carácter elitista, etnocéntrica y monocultural. La política educacional argentina, ha reproducido las relaciones de poder que se dan en la sociedad, todo es parte de una sola cultura, de un solo imaginario que se impone a los demás, desconociendo la existencia de cualquier otra cultura distinta a la dominante (Norgvlamtuleayiñ, 2009).

Desde esta perspectiva, se pueden elaborar dos líneas de análisis, en la comprensión de la practicas educativas homogeneizantes, la primera: la necesidad de interrogar el dispositivo de homogeneización cultural, visibilizando cómo se despoja toda práctica educativa de su contenido ideológico y político, en una especie de educación como sinónimo de adaptación a un orden instituido como el único mundo posible, considerando a la razón instrumental como la única forma de conocimiento validado. En segundo lugar, la lógica de vaciamiento de alternativas y movimientos contra hegemónicos a ese orden y su capitalización como reforzamiento del orden dominante. Dos ejemplos: la educación popular latinoamericana como práctica histórica y corriente pedagógica, está ligada a procesos sociales y culturales regionales, la obra de Freire y otro/as pensadores/as regionales surge articulada con movimientos culturales y políticos del nordeste brasilero, pero también en consonancia con el ambiente revolucionario que se vivía en toda la región y el resto del mundo, "revolución cubana", "luchas de liberación en áfrica", "revolución cultural china", "revueltas de mayo de 1968”, incluso la renovación de la Iglesia Católica promovida por el Concilio Vaticano II, entre otros procesos sociopolíticos, todos enmarcados en una lógica representada por una pedagogía denominada "pedagogía del oprimido". El comienzo de los "terrorismos de estado" en la región, con sus metodologías represiones, persecuciones, desapariciones y demás, fue también una puerta de entrada al más crudo neoliberalismo y vaciamiento cultural, lo que provocó la aparición de prácticas pedagógicas que buscaban (y en muchos casos lo consiguieron) consolidar un dispositivo educativo individualista, positivista y a-histórico.

Por este motivo, la historia de la educación en la región, solamente registra como propuestas pedagógicas aquellas que se produjeron dentro del sistema educativo dominante, en el interior del sistema pedagógico hegemónico, sin entender que precisamente ese carácter hegemónico surgía de la incorporación- subordinación de las demandas educativas populares a la lógica educativa dominante (Puiggrós, 1986). En cierta medida, el sistema educativo expresa una de 


\section{Pedagogias Críticas y Psicología Latinoamericana: diálogos para una pedagogía desde el sur global}

las aristas de lo que Aníbal Quijano denomina la colonialidad del poder, mediante sus prácticas pedagógicas destinadas a imponer pedagógicamente un poder hegemónico colonial.

Simón Rodríguez, considerado el primer maestro latinoamericano y maestro de Simón Bolívar, pensaba hace más de dos siglos, que la escuela debía ser no solo un lugar de trasmisión de conocimiento, también debía ser un espacio para la creación, para el trabajo, donde se educara al ser humano de un modo holístico, promoviendo otra capacidad de pensar y otra posibilidad de hacer, donde no solo se debían conocer sus deberes, también debían conocer sus derechos. Pensaba que la educación no resulta un hecho autónomo, sino un componente básico en el mantenimiento de las estructuras sociales, la educación en el nivel de superestructura del sistema social.

Tuvieron que trascurrir muchos años y muchas luchas para que emergiera una corriente pedagógica que representara algunas experiencias de la región. Fue Paulo Freire; quien supo cuestionar la asepsia de las prácticas educativas hegemónicas y afirmar que la educación nunca es neutra, que toda práctica educativa es política y toda práctica política es educativa, de esta manera, proponiendo a la educación popular como una práctica y teoría que puede acompañar procesos de transformación social en la región. En síntesis, los sujetos sociales se constituyen en el plano de las situaciones materiales, como en las de la cultura, porque ambas son dimensiones de una misma realidad. Esto lleva a plantear la necesidad de estudiar la dimensión simbólica de todas las prácticas sociales y a reconocer que la cultura es fundamentalmente para conocer e incidir sobre los factores populares (Torres Carrillo, 2013). En esa encrucijada coyuntural, la comprensión de la colonialidad del poder, permite pensar en una educación intercultural regional como posibilidad de trasformación social.

\section{Decolonialidad de la razón instrumental: aportes para la emergencia de otros sabers}

Aníbal Quijano constituye una de las más destacadas interpretaciones sobre la constitución de América Latina, y sobre todo la incidencia de la colonialidad del poder, el eurocentrismo y la globalización como nuevas rearticulaciones del poder colonial. La perspectiva, permite ampliar los niveles de análisis en cuanto a la construcción de la subjetividad regional, desde su lectura, el poder mundialmente hegemónico, conserva en su matriz, elementos de colonialidad que mantienen a la región en una situación de sumisión ante el nuevo patrón de orden mundial. Este punto es central, porque la discusión nodular deja de centrarse solamente en la colonialidad como equivalencia a una dominación colonial material, ahora en adelante, será su matriz cultural, simbólica, representacional más persecutoria y amenazante que la dominación material.

De esta manera, la crítica a la racionalización instrumental que conlleva la matriz de la colonialidad del poder de la modernidad, se interroga y se problematiza en el camino de la decolonialidad del poder, pero esta discusión, no solo creemos que le compete sustancialmente al campo de un Psicología Latinoamericana, también implica a las ciencias sociales en general, como una forma de recuperar la razón histórica, como método de análisis de la región. 
Lo interesante de la lectura de Quijano en cuanto construcción hegemónica del saber y determinación de subjetividades coloniales, resulta ser que no solo da cuenta del genocidio que se cometió con la llegada de los conquistadores, es decir el de masacrar personas, también fue masacrar saberes, conocimientos, producción de símbolos, modos de significación, y un sinfín de genocidios que acompañaron al de las personas, genocidios con los que aun convivimos cotidianamente, en palabras de De Sousa Santos: epistemicídios. La lectura de Quijano consiste en poder describir, como a medida que la represión iba cediendo en su carácter inmediato, se fue imponiendo en sus usos propios, patrones de expresión de la cultura etnocéntrica, que comienza a delinear las pautas de control social, que luego comenzaron a desarrollarse de modo más sutil y sofisticado.

"Los colonizadores impusieron también una imagen mistificada de sus propios patrones de producción de conocimiento y significaciones, primero lejos del acceso de los dominados, mas tarde, los enseñaron de modo parcial y selectivo, para coaptar en algunos dominados en algunas instancias del poder de los dominados. Entonces la cultura europea se convirtió, además, en una seducción: daba acceso al poder. La europeización cultural se convirtió en una aspiración en fin para el "desarrollo". La cultura europea paso a ser u modelo cultural universal”. (Quijano, 1992: 13).

A las subjetividades regionales, una vez despojadas de sus patrones de conocimiento y expresión, se les fueron imponiendo los patrones culturales de los dominantes, totalizando las subjetividades, en cierta medida, homogeneizando las expresiones en una sola subjetividad, la subjetividad racional, moderna y eurocéntrada, una subjetividad única, impermeable a las diversidades.

Para Aníbal Quijano, el paradigma de producción de conocimiento eurocéntrico, tiene un principio fundante, que es el conocimiento como productor de una relación entre sujeto y objeto, cimiento que vendrá a legitimar toda una construcción del sujeto que quedará, de este modo, relegado a la categoría de sujeto/objeto de conocimiento. Esta categorización del sujeto cognoscente, racional e individualista del modelo eurocéntrico, no resulta casual, es decir, plantea en cierta medida, la relación de un individuo que conoce (dominador) algo (dominado), en una especie de concepción de conocimiento, muy ligada a la concepción de propiedad. La asociación entre el sujeto que conoce y algo, no solo va a conllevar la hegemonía de la colonialidad del poder, ahora en la matriz de la colonialidad del saber, también va a conllevar la ausencia o la negación del otro, que no esté tipificado en la categoría del dominador (europeo). La subjetividad regional, va totalizándose bajo la órbita de la colonialidad del poder capitalista en la equivalencia de conocer y poseer.

De ahora en adelante, el mundo solo podrá ser racional, moderno, civilizado, y solo una cultura podrá contener sujetos, todo lo demás, en la consecuente clasificación racial, será objeto de conocimiento; desde esa clasificación y nueva categorización que se mantiene aún vigente en los epicentros del poder, la cultura euro-céntrica será sujeto de conocimiento y todo lo demás, objeto de conocimiento-posesión, obturando toda posibilidad de comunicación, intercambio y construcción intersubjetiva, ya que, entre sujeto y objeto solo es posible una relación de exterioridad. En esa construcción de una totalidad histórica, homogénea y tan insistentemente repetido en los centros educativos, 
"Nada sorprende, en consecuencia, que la historia fuera concebida como un continum evolutivo desde lo primitivo a lo civilizado, de lo tradicional a lo moderno, de lo salvaje a lo racional, del pre capitalismo capitalismo, etc. Y que Europa se pensara a sí misma como el espejo del futuro, de todas las demás sociedades y culturas, como el modo avanzado de la historia de toda la especie. Lo que no deja de ser sorprendente, de todos modos, es que Europa, lograra imponer ese espejismo a la práctica totalidad de las culturas que colonizó. Y mucho más, que semejante quimera sea aún hoy tan atractiva y para tantos." (Quijano, 1992: 18)

Según Quijano, la descolonización radica precisamente en la reconstitución epistemológica, en el cuestionamiento de los mandatos coloniales que implícitamente dirigen la geopolítica del conocimiento desde la matriz del poder, que presenta en su composición, la continuamente renovada cara de la colonialidad, siempre vigente.

La colonialidad del saber, es el dispositivo que inhabilitará la construcción y producción de conocimiento que no reproduzca los lineamientos y los mandatos de la racionalidad y la modernidad europea. Por lo tanto, la decolonialidad del poder, posibilita cuestionar el paradigma de la totalidad, para dar paso a una nueva comunicación intercultural, un intercambio de saberes, experiencias, significaciones como sustento y legitimidad epistemológica de otra racionalidad. Los aportes de Quijano, también apuntan comprender el lugar y la significación de la aparición de los Estado-Nación en la vida de los pueblos originarios y cómo el mismo, aparece no solo como legalizador de la apropiación y legitimación del despojo a los pueblos originarios, sino también como uno de los grandes responsables de planificar los mandatos totalizantes de occidente. Al comprender el lugar del Estado en la rearticulación del poder colonial, veremos con mayor claridad al sistema educativo como aparto ideológico del Estado, como una forma de profundizar el mandato totalizante de occidente.

Una vez configurada la aparición del moderno Estado-nación, la sociedad toma la forma y se reconfigura en la denominada "identidad nacional", configurando lo que Quijano menciona como una estructura de poder que va a articular formas de existencia social dispersas y diversas en una totalidad única, al respecto dice:

“Consecuentemente todo Estado-nación posible es una estructura de poder, del mismo modo que es producto del poder. En otros términos, del modo en que han quedado configuradas las disputas por el control del trabajo, sus recursos y productos; del sexo, sus recursos y productos; de la autoridad y de su especifica violencia; de la intersubjetividad y del conocimiento." (Quijano, 1992: 226)

Finalmente, termina dando cuenta de los intereses que representaba para el capitalismo global, la emergencia de los modernos Estados-Nación en la región, resultando una rearticulación del poder colonial y profundizando la homogeneidad cultural en nuestras regiones.

\section{La Educación Popular y la decolonialidad del saber}

La necesidad de comprender la colonialidad del poder, sus nuevas articulaciones, y la urgencia de problematizar sus matrices, lleva a pensar que la educación popular puede resultar una 
herramienta de concienciación política y cultural, en cuanto problematización de la colonialidad del saber, una de las aristas de la colonialidad del poder, para una aproximación a una educación intercultural.

En la descripción de la colonialidad del poder de Quijano, se puede comprender cómo funciona el saber dominante como justificación del poder. Esa comprensión podemos ejemplificarla con lo que nos dice Gentili, en cuanto al rol de la educación y lo que significa para los poderosos, dice:

"Parece más bien que a los empresarios latinoamericanos la educación les aporta una coartada, un pretexto para justificar sus beneficios y oportunidades en sociedades marcadas por la injusticia y la desigualdad. También para explicar, con un tono aparentemente comprometido, por qué millones de personas continúan viviendo en la miseria mientras sus fortunas no paran de crecer (Gentili, 2015.: 101)

Como venimos sosteniendo, una de las resistencias a los mandatos totalizantes y unidimensionales de la educación hegemónica, es el conocimiento y la reconstrucción de lo local. Por lo desarrollado hasta ahora, hemos podido comprender que el conocimiento en general, aunque avance hacia la super-especialización y profesionalización, aumenta las brechas sociales y la consolidación de un poder hegemónico, reafirmando lo que venimos sosteniendo, en cuanto a que el paradigma de la ciencia moderna occidental, avanza por especialización, fragmentación, parcialización y por disociación. Pretendiendo ser un conocimiento disciplinar, termina siendo un conocimiento disciplinado, segrega y fragmenta en cuanto mayor profesionalización conlleva. Esta parcelación del conocimiento, termina justificado en determinadas ocasiones, arbitrariamente con sus propias medidas, es decir, reproduciendo con otro ropaje lo que se pretendía solucionar; de esta manera, se generan nuevos campos de estudios, nuevas especializaciones, nuevos métodos, nuevos títulos, para contrarrestar las carencias de los campos antiguos, y así continuar reproduciendo el mismo modelo. El problema no está en las disciplinas, el campo o el método, el dilema está en el paradigma, en la epistemología y la ontología que reproduce la colonialidad del poder.

"La ciencia moderna nos legó un conocimiento funcional del mundo que alargó extraordinariamente nuestra perspectiva de sobrevivencia. Hoy no se trata tanto de sobrevivir, como de saber vivir" (De Sousa Santos, 2009: 52).

En ese sentido, se reconsidera lo local, lo barrial, lo regional, como una forma de redescubrir y recuperar conocimiento que recupere otras prácticas y otros modos de vinculación social. Ahora bien, en la reconstrucción y resignificación de lo local, deben problematizarse los marcos conceptuales que determinan y condicionan la construcción de conocimiento. Primero, las ciencias sociales son una ciencia subjetiva, por ende, los sistemas de creencias, ideologías, juicios de valor no están antes ni después de las explicaciones científicas, son inherentes a la misma explicación: el sujeto cognoscente, es sujeto empírico, eso no le imprime ni mayor ni menor rigor investigativo, es simplemente otra posición epistémica a la ciencia dominante. En segundo lugar, las prácticas educativas, pedagógicas, psicológicas nunca son neutras, toda práctica educativa es política, y así toda practica y discurso político es educativo (Freire, 2002), solamente en esta reconfiguración, podemos comprender los intentos de desconexión entre la educación y los sistemas de poder, de ahora en más, la educación no 


\section{Pedagogias Críticas y Psicología Latinoamericana: diálogos para una pedagogía desde el sur global}

como hecho autónomo, sino como un componente decisivo en el mantenimiento de las estructuras sociales, en definitiva se convierte en un hecho decisivo en la rearticulación del poder (Quijano, 2000).

En esa reconfiguración, se puede ver con claridad la esencia de la educación dominante, denominada por Freire como "bancaria" (Freire, 2002), con sus principales elementos, por un lado, el educador disciplina, es quien habla, prescribe, es quien sabe, es sujeto, y por otro lado, el educando pasivamente, objeto de todos los mandatos del sistema, lo cual enmarca una práctica pedagógica, inserta en un marco sociopolítico verticalista, autoritario, elitista, positivista, eurocéntrico y capitalista, en ese engranaje funcional, se manifiesta la colonialidad del saber, como brazo ejecutor de la colonialidad del poder.

Por este motivo, la propuesta de reconstrucción de lo local, como la recuperación y resignificación de saberes y experiencias regionales, también construye un cimiento epistémico y un marco político diferente, donde la "pedagogía del oprimido" en toda su dimensión, pueda ser considerada como sostenía Freire, como una "práctica de libertad". Una pedagogía que parte desde cada particularidad territorial. En esa práctica de libertad, donde las historias locales tengan la posibilidad de redescubrirse y reencontrarse, es ahí, donde se resinificará la subjetividad determinada por la matriz hegemónica colonial. En esa nueva configuración, considerando el método de concientización, como "practica de libertad", en cuanto posibilita el encuentro con su propia realidad, dialogar, intercambiar saberes, un encuentro horizontal en la valoración del conocimiento, constitutivamente conlleva una decolonialidad del saber de la geopolítica del conocimiento. Es en ese nuevo escenario donde encuentran legitimidad determinadas prácticas para un diálogo intercultural:

"Ahora, ya nadie educa a nadie, así como tampoco nadie se educa a sí mismo, los hombres se educan en comunión, y el mundo es el mediador.” (Freire, 2002: 85)

Es decir, la praxis pedagógica transformadora de la realidad, que se convierte en la pedagogía de la esperanza para Freire, viene a resignificar intersubjetivamente nuestros encuentros y modos de vincularnos, se constituye en una poderosa herramientas de concienciación social, y así intentar superar la desilusión y el fatalismo latinoamericano -llevado a categoría de análisis psicosocial por Ignacio Martín-Baró, en el que en definitiva, nos han sumido los propietarios de la colonialidad del poder (Martin-Baro, 1998). Por este motivo, Paulo Freire sintetiza la pedagogía del oprimido en dos momentos fundamentales e indispensables en el proceso de liberación:

"La pedagogía del oprimido, como pedagogía humanista y liberadora, tendrá pues, dos momentos distintos pero interrelacionados. El primero, el cual los oprimidos van descubriendo el mundo de la opresión y se van comprometiendo, en la praxis, con su transformación y, el segundo, en que una vez transformada la realidad opresora, esta pedagogía deja de ser del oprimido y pasa a ser la pedagogía de los hombres en proceso de permanente liberación (Freire, 2002: 50).

Los dos procesos que indica Freire, permiten visualizar que en reiteradas ocasione el saber científico se legitima como tal, desacreditando, deslegitimando y en algunas ocasiones 
destituyendo saberes que no resistan la lógica de la razón instrumental. En este sentido, como sostiene María Fiori en la introducción a la pedagogía del oprimido, dice:

"En un régimen de dominación de conciencias, en los que más trabajan menos pueden decir sus palabras, y en que inmensas multitudes ni siquiera tiene condiciones para trabajar, los dominadores mantienen el monopolio de la palabra con que mistifican, masifican y dominan. En esa situación, los dominados, para decir su palabra, tienen que luchar para tomarla. Aprender a tomarla de los que la retienen y niegan a los demás, es un difícil pero imprescindible aprendizaje: es la "pedagogía del oprimido". (María Fiori en Freire, 2002: 26)

Los dos procesos que plantea Freire en la pedagogía del oprimido, transcienden a al análisis de la dimensión educativa, y comienzan a interrogar la dimensión cultural de la matriz colonial occidental:

"En cualquiera de estos momentos, será siempre la acción profunda a través de la cual se enfrentará, culturalmente, la cultura de la dominación. En el primer momento, mediante el cambio de percepción del mundo opresor, por parte de los oprimidos y, en el segundo, por la expulsión de los mitos creados y desarrollados en la estructura opresora, que se mantienen como aspectos míticos, en la nueva estructura que surge de la transformación revolucionaria." (Freire, 2002: 50)

Freire sistematiza una serie de experiencias diversas, y diseña una forma de interrogar la colonialidad del saber, sus afirmaciones en cuanto recuperar y revisar el diálogo como proceso de concientización, permiten redescubrir y resignificar nuestra historicidad. La práctica pedagógica como práctica política, la revalorización de las historias subjetivas, la legitimación del saber popular como condición previa e indispensable de un cambio político, económico, cultural y social, son una variedad de prácticas pedagógicas que ponen en tensión los mandatos totalizantes del mundo capitalista, colonial y eurocentrado. Freire, habilita un proceso de alternativa a la descolonización del saber cómo principio de un proceso de descolonizar el poder.

\section{Educación Popular y Educación Intercultural crítica}

En el discurso oficial, la educación es la única capaz de solucionar los problemas de la región, y de esta manera, serán los organismos y las instituciones dominantes las encargadas de prescribir la solución. Esta coartada del poder hegemónico según Gentili (2015), hace que se reciclen políticas educativas, alternando en la forma, pero inamovibles en su matriz. Por este motivo y a la luz de las consecuencias de las políticas educativas de los últimos siglos, podemos afirmar que cualquier política educativa, por más progresista que se presente y matizada con discursos elocuentes, concebida sobre la concepción epistemológica de sujeto antropocéntrico, eurocentrico, capitalista y colonial, en cualquiera de sus nuevas facetas, terminará siendo, en términos de Quijano, una nueva rearticulación del poder, para continuar promovieron una colonialidad del saber.

El intento de superación de la noción de sujeto epistémico moderno occidental permite pensar a la educación popular como metodología, teoría, práctica, fundamentación epistémica, 


\section{Pedagogias Críticas y Psicología Latinoamericana: diálogos para una pedagogía desde el sur global}

trascendiendo la reducción de la educación popular como una educación para adultos, que en definitiva fue donde tuvo su mayor experiencia, como propuesta epistemológica que interpela la matriz colonial de la colonialidad del saber, que en definitiva, reproduce y rearticula la colonialidad del poder, globalizante y totalitaria del capitalismo. En esa otra perspectiva, la educación popular puede resubjetivizar las subjetividades totalizantes de la colonialidad del poder, para habilitar nuevos saberes y nuevas creencias, propias de la riqueza regional. El proceso de problematización del pensamiento hegemónico, para la reemergencia de nuevas historias y la resignificación de nuevos saberes y nuevas subjetividades históricas, debe ser gradual, critico, interpelante, en el cual el sujeto asume una posición histórica, económica, social, una posición de acción-reflexión que lo lleva a asumir una nueva posición epistemológica.

"lo utópico para mí, no es lo irrealizable; la utopía no es el idealismo, es la dialectización de los actos de denunciar y anunciar la estructura deshumanizante y de anunciar la estructura humanizante. Por esta razón, la utopía es también compromiso histórico.”(Freire, 1974: 31)

Este giro epistemológico que podría tomar la educación respecto a la concepción de sujeto, no es un giro en el vacío como se menciona anteriormente, algunos movimientos regionales dan cuenta de alternativas políticas, en cuanto a una nueva configuración del sujeto histórico regional, por ejemplo, respecto a las experiencias de Bolivia, dice Evo Morales, en el prologo a la constitución de Bolivia como estado plurinacional:

"Mientras que los pueblos indígenas proponen para el mundo el vivir bien, el capitalismo se basa en el vivir mejor, que no es otra cosa que vivir a costa de otro (Morales, 2011: 9).

En esas nuevas experiencias políticas regionales, emerge la necesidad de resignificar los marcos epistemológicos y ontológicos que dirigen la praxis de las pedagogías latinoamericanas, emerge la posibilidad de comprender la interculturalidad, no como política de organismos internacionales (BM, FMI, BID y demás), todo lo contrario, como interculturalidad histórica, como posibilidad de diálogos entre culturas, como proyecto político que trascienda lo educativo, en síntesis, como un nuevo ordenamiento social.

La comprensión de las metamorfosis de la colonialidad del poder en la región, y la reemergencia de nuevas cosmovisiones políticas latinoamericanas, conlleva la necesidad de un compromiso activo desde las ciencias sociales en general y la pedagogía y la psicología en particular. La revisión de la razón histórica como herramienta en la redefinición de la una pedagogía critica y desde el sur global, permite superar los paradigmas reduccionistas, cuantitativos y analíticos de la razón instrumental que, en palabras de Quijano, rearticulan la colonialidad del poder y la colonialidad del saber. En esa posición histórica, política e epistemológica, toma dimensión lo que Catherine Walsh define como Interculturalidad, en una especie de reencuentro con nuestra riqueza cultural:

"La interculturalidad debe ser entendida como designio y propuesta de sociedad, como proyecto político, social, epistémico, y ético dirigido a la transformación estructural y socio histórica, asentado en la construcción entre todo de una sociedad 
radicalmente distinta. Una transformación y construcción que no queden en el enunciado, el discurso o la pura imaginación; por el contrario, requiere de un accionar en cada instancia social, política, educativa y Humana." (Walsh, 2010: 79).

El desafío de recuperar, repensar y redescubrir corrientes y movimientos pedagógicos que surgen en la región de América Latina, permiten avanzar en construir diseños pedagógicos desde las particularidades y historias locales para la real transformación social del sur Global.

\section{Conclusión}

Los diseños pedagógicos, educativos, curriculares diseñados por los organismos internaciones e implementados por los Estados Nacionales en América Latina general y en Argentina en particular, parecen continuar respondiendo a la geopolítica del conocimiento, que no es otra cosa, que la negación y el desconocimiento de las particularidades históricas, políticas, culturales, epistémicas, propias de la región del sur global. La educación hegemónica es un componente básico en el mantenimiento de las estructuras sociales y coloniales. En ese sentido, la colonialidad del poder se expresa mediante el diseño de políticas y prácticas destinadas a imponer pedagógicamente un poder hegemónico colonial.

La necesidad de recuperar y resignificar corrientes pedagógicas propias de la región de América Latina, permiten problematizar la unidimensionalidad eurocéntrica de la geopolítica del conocimiento, de esta manera, habilitar las emergencias de "otras" epistemologías de la región, que responden a otras culturas y cosmovisiones de los territorios de América Latina. Los aportes de las corrientes pedagógicas críticas, la educación liberadora de Paulo Freire, las educaciones populares, la psicología de la liberación, entre otras, permiten redescubrir prácticas pedagógicas que interpelan las subjetividades totalizantes que impone el sistema educativo actual. Paulo Freire en particular, diseña una pedagogía que interroga la colonialidad del saber, revalorizando la experiencia subjetiva pero situada en un contexto histórico, político y cultural, un punto de partida en descolonizar el saber para descolonizar el poder. En ese sentido, también la interculturalidad como propuesta pedagógica, política y cultural, viene a trascender la subjetividad totalizada y universal de los diseños pedagógicos coloniales para diseñar políticas educativas en términos de diálogos intersubjetivos, propios del pluriverso cultural que implica la región de América Latina.

Por último, La necesidad de reinventar las experiencias pedagógicas del sur global, a la luz de los diversos movimientos sociales, políticos, populares, indígenas, feministas entre otros, podrían habilitar transformaciones sentipensantes y practicas transformadoras que promuevan diseños pedagógicos alternativos a los diseñados por la geopolítica del conocimiento. En definitiva, es la memoria, el dialogo y la pregunta lo que incomoda y desafía a las herencias coloniales que sostiene la ciencia moderna y el capitalismo colonial vigente.

\section{Referencias}

Castro-Gimez y Grosfoguel (compiladores, 2007) Reflexiones para una diversidad epistémica más allá del capitalismo global. Bogotá, Colombia: Siglo del hombre editores, Universidad central de Bogotá.

Ziegler, J. (2002) Los nuevos amos del mundo. Barcelona, España: Editorial destino.

Torres Carrillo, A. (2007) Educación popular: trayectoria y actualidad. Venezuela: Editorial Universidad Bolivariana de Venezuela.

Bautista, J. (2012). Hacia la descolonización de la ciencia social latinoamericana. La Paz, Bolivia: Editorial rincón ediciones. 


\section{Pedagogías Críticas y Psicología Latinoamericana: diálogos para una pedagogía desde el sur global}

Bonal, X. Tarabini, A. (2005). ¿Puede la educación erradicar la pobreza? Seminario de análisis de la política social, universidad de Barcelona. España. Disponible en: http://www.researchgate.net/publication/39214354

Centro de educación mapuche Norgvlamtuleayiñ (2000) Educación para un Neuquen intercultural. Neuquén, Argentina: Editorial Mimeo.

Coraggio, L. (2004) la gente o el capital: desarrollo local y economía del trabajo. Buenos Aires: Editorial Espacio.

De Sousa Santos, B. (2009). Una epistemología del sur: la reinvención del conocimiento y la emancipación social. México: Editorial Siglo Veintiuno.

Elorza, E. (2015) Economía Política en la Transición. Buenos Aires: Editorial FISYP.

Enriquez, P., Di Pascuale, V. (2012). Desigualdad social, pobreza y educación: lectura de diversas posiciones sociopolítica. San Luis, Argentina.

Estela Fernández Nadal y Gustavo David Silnik “Entrevista a Franz Joseph Hinkelammert” en Cuadernos del Pensamiento Crítico Latinoamericano No 43. CLACSO, junio de 2011. Publicado en La Jornada de México, Página 12 de Argentina y Le Monde Diplomatiquede Bolivia, Chile y España.

Filmus, D. (1996) Estado, sociedad y educación en la Argentina de fin de siglo: procesos y desafíos. Buenos Aires, Argentina: Editorial Troquel.

Freire, A; Faundez, A. (2013) Por una pedagogía de la pregunta.Buenos Aires: Editorial Siglo Veintiuno.

Freire, P. (1974). Concientización. Buenos Aires: Editorial Búsqueda.

Freire, P. (2002) Pedagogía del Oprimido. Buenos Aires: Editorial Siglo Veintiuno.

Gentili, P. (2015). América Latina, entre la desigualdad y la esperanza. Buenos Aires: Editorial Siglo Veintiuno.

Goldentul, A. (2012). Aportes, ideas y problemas en Aníbal Quijano y Orlando Fals Borda: una lectura posible desde la descolonización del saber. Universidad de Buenos Aires. Disponible en: http://jornadassociologia.fahce.unlp.edu.ar

Martin-Baro (1986) Hacia una psicología de la liberación. San Salvador, El Salvador: Editorial UCA Editores.

Puiggros, A. (1986). Democracia y autoritarismo en la pedagogía argentina y latinoamericana.Buenos Aires: Editorial Galerna.

Quijano, A. (1988). Modernidad, identidad y utopía en América latina. Lima, Perú: Editorial Sociedad y Políticas.

Quijano, A. (1992). Colonialidad y modernidad/racionalidad. Lima, Perú: Perú Indígena.

Quijano, A. (2000). Colonialidad del poder, Eurocentrismo y América Latina. Buenos Aires: PeruIndigena.

Quintero, P. (2010). Notas sobre la teoría de la colonialidad del poder y la estructuración de la sociedad en América Latina.Buenos Aires: Papeles de Trabajo No19-junio 2010. UBA.

Roig, A (2008). El pensamiento latinoamericano y su aventura. Mendoza, Argentina: Editorial El andariego.

Tarabini, A. (2010). El binomio educación-pobreza: un análisis de su papel en la agenda global de desarrollo. Disponible en revista innovación educativa, vol. 11, numero 54, enero-marzo 2011.

Torres Carrillo, A. (2011). Educación Popular: trayecto y actualidad. Venezuela: Dirección general de producción y recreación de saberes.

Walsh, C. (2010). Interculturalidad crítica y educación intercultural. La Paz. Bolivia: Instituto integral de integración Andrés Bello.

Zibechi, R. (2011) Latiendo resistencia: mundos nuevos y guerras del despojo. Málaga, España: Editorial Zambra iniciativas sociales. 